\title{
Promoting Student Interest in Family Medicine Through National Conference Attendance
}

\author{
Valerie L. Hearns, MD | Susan M. Anderson, MD | Wafa Akkad, MD | Benjamin Meyerink, MD | \\ William E. Schweinle, PhD
}

Published: 10/16/2017 | DOI: 10.22454/PRiMER.2017.580198

\section{Abstract}

Introduction: The University of South Dakota Sanford School of Medicine (USDSSOM) had success in preparing students to enter family medicine. A sharp decline in students choosing the specialty became noticeable in 2004. In 2005 , only $10.2 \%$ of the graduating class entered family medicine residency programs. To reverse this trend, the Department of Family Medicine partnered with the South Dakota Academy of Family Physicians (SDAFP) chapter that year to send students to the American Academy of Family Physicians (AAFP) National Conference of Family Medicine Residents and Medical Students. This report examines the influence of national conference attendance on career choice. While many factors influence student choice, conference attendance served as an additive method for recruitment.

Methods: Internal departmental records on national conference attendance and subsequent National Resident Matching Program (NRMP) data were reviewed retrospectively, to determine if a correlation existed between conference attendance and choice of family medicine as a specialty. Chi-squared analysis was utilized to further examine this relationship.

Results: The association between conference attendance and number of times attending is significant $\left(\chi^{2}\right.$ $=6.78, P<.05)$. The recent data show that this intervention has resurrected student interest in family medicine, with USDSSOM now exceeding the NRMP average for family medicine.

Conclusions: A positive correlation exists between national conference attendance and medical student choice to enter family medicine residency programs. This intervention may be used by more medical schools wishing to promote family medicine in order to help meet our nation's primary care workforce needs.

\section{Introduction}

The Council on Graduate Medical Education 20th Report, "Advancing Primary Care", stressed the need for policies that would increase the percentage of primary care physicians to a minimum of $40 \%{ }^{1}$ This was deemed necessary in order to achieve the Triple Aim of health care-better health, better health care, and reduced costs. ${ }^{2}$ The United States has a primary care workforce shortage that will worsen if the percentage of medical school graduates entering family medicine residencies does not increase significantly. It should be the responsibility of all US medical schools to contribute to this workforce need.

The mission statement of the University of South Dakota School of Medicine (USDSSOM) emphasizes family medicine, resulting in a rich history of graduating medical students who entered family medicine residency programs. This accomplishment was nationally recognized with American Academy of Family Physicians (AAFP) Gold, Silver, and Top Ten awards over the years. From 1995 to 1997 the 3-year average of USDSSOM graduating medical students entering family medicine residency programs was $37.1 \%$. That average fell to $12.1 \%$ from 2005 to 
2007. This decline was also experienced across North America. ${ }^{3}$

In support of its mission statement, USDSSOM admission policies favor students who express an interest in family and rural medicine. ${ }^{4}$ Other positive factors included an active and well-received family medicine interest group, required clerkships in family medicine which include rural experiences, and positive faculty role models within the department, medical school administration, and the community. ${ }^{1,4,5}$

It became apparent that something more needed to be done. In 2005, the decision was made to sponsor students to attend the AAFP National Conference of Family Medicine Residents and Medical Students. It was hoped that this additional intervention would increase students' interest in family medicine as a specialty and thus increase residency choice of family medicine.

After 10 years, an analysis was performed to look at outcomes. The inference is that national conference attendance increased the percentage of medical students entering family medicine residency programs. These methods and findings should be translatable to other medical schools that need to address this situation.

\section{Methods}

Students were notified of this opportunity via email and posting of newsletters. A simple application was required and all students were given the opportunity to apply. Presumptive specialty choice did not influence selection of students to attend. This effort has been financially supported by the South Dakota Academy of Family Physicians (SDAFP) chapter and AAFP Foundation Family Medicine Leads Scholarships.

National Resident Matching Program results were reviewed to determine students' specialty choice following conference attendance. Additionally, data of graduates' residency specialty choice prior to the offering of this intervention were reviewed. This retrospective cohort study allowed the investigators to formulate ideas about possible associations and relationships. Regression analysis of the data was done to further estimate the strength of the relationship between conference attendance and specialty choice. An additional chi-squared analysis was estimated for the sample that included only students who attended one or two conferences. This project was approved by the University of South Dakota, Office of Human Subjects Protection IRB.

\section{Results}

From 2005 through 2016, 89 sponsored students attended the AAFP National Conference of Family Medicine Residents and Medical Students. This represents $14.4 \%$ of all students enrolled in the MD program during that timeframe. On average, seven students attend each year, with a range of 3 to 12 . Students were allowed to attend the conference more than once. Attending the conference multiple times resulted in more students choosing family medicine residency programs.

Figure 1 depicts USDSSOM NRMP results of students who attended the national conference one time. Multiple specialties are represented, with the majority of students matching in family medicine. Figure 2 depicts USDSSOM NRMP results of students who attended the national conference two or more times and shows an even greater percentage of this cohort matching in family medicine.

Of the 62 graduates who attended the national conference, 37 (60\%) entered family medicine residency programs. During the timeframe of study, our average is $15.4 \%$, compared to $8-9 \%$ nationally. ${ }^{6}$

MS3 and MS4 students accounted for $80 \%$ of conference attendees. When asked to describe their national conference experience, attendees commented on the value of obtaining information about family medicine residency programs and the positive outlook regarding the future of family medicine.

Table 1 depicts the relationship between the number of national conferences attended and the proportion of students who attended one, two, or three conferences and entered a family medicine residency. There was a significant association between the number of conferences attended and the proportion of attendees who entered family medicine residencies $\left(X^{2}=6.78, P<.05\right)$. Because there were only five students in the sample who attended 
three national conferences, this result may be unreliable. Therefore those five students were excluded from the Chisquared analysis. Results in the chi-squared analysis were similar and significant $\left(\chi^{2}=5.65, P<.05\right)$. Thus, it can be concluded that there is an association between the number of national conferences a student attends and the likelihood that that student will enter a family medicine residency.

\section{Conclusion}

Sponsoring and encouraging medical student attendance at the AAFP National Conference positively influenced medical student choice to enter family medicine, especially among students who attended more than once. While many factors influence student specialty choice, the impact of this conference is significant. Students who attended testified to its effect on career planning.

This study is limited by lack of assessment of other factors known to influence specialty selection and of reasons students who attended chose other specialties. Future studies should explore these variables. USDSSOM will continue to question students who partake in this conference to further examine and justify its impact in recruitment. Additional time and study may further elucidate the impact of attending the national conference two or three times.

Studies continue to demonstrate the need for medical schools across the country to produce more family medicine graduates who will help meet the demands of our growing population. ${ }^{1}$ With increasing burdens upon the health care system and a substantial shortage of family physicians, solutions to reverse this trend within undergraduate medical education are vital. In partnership with the SDAFP, USDSSOM will continue to support students attending the national conference, while maintaining admission policies and curricula that promote family medicine. The hope is that other medical schools could learn from this data and institute similar programs to improve family medicine recruitment to help meet our nation's primary care workforce needs.

\section{Tables and Figures}

Table 1: Number of AAFP Conferences Attended Relative to Proportion of All Attendees Who Entered a Family Medicine Residency

\begin{tabular}{|c|c|c|c|}
\hline No. of AAFP Conferences Attended & 1 & 2 & 3 \\
\hline $\begin{array}{c}\text { Proportion in family medicine residencies } \\
\text { (freq.) }\end{array}$ & $\begin{array}{c}51 \% \\
(24 / 47)\end{array}$ & $90 \%$ & $80 \%$ \\
$(9 / 10)$ & $(4 / 5)$ \\
\hline
\end{tabular}


Figure 1: NRMP Results of One-Time National Conference Attendance

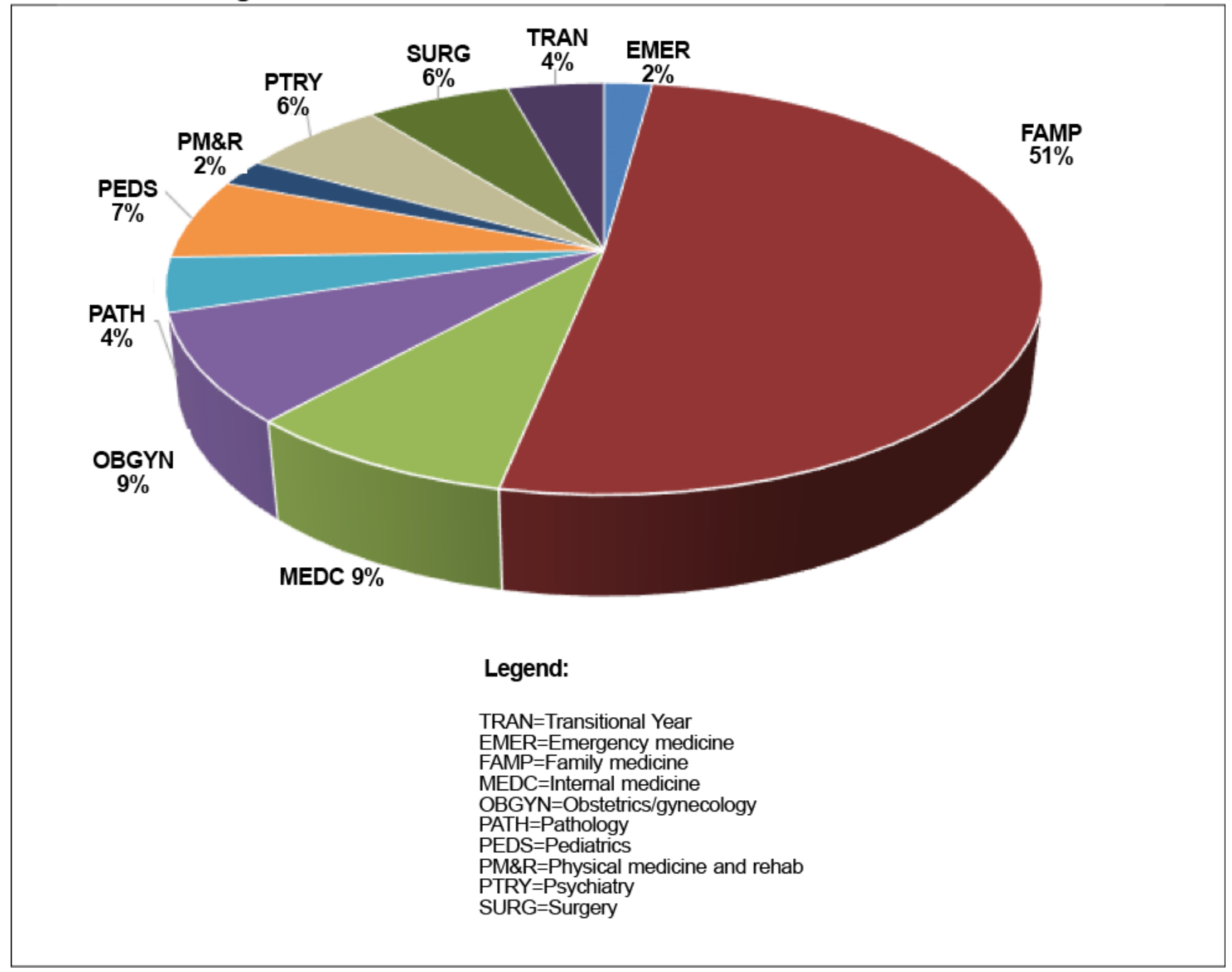

Figure 2: NRMP Results of National Conference Attendence Two or More Times

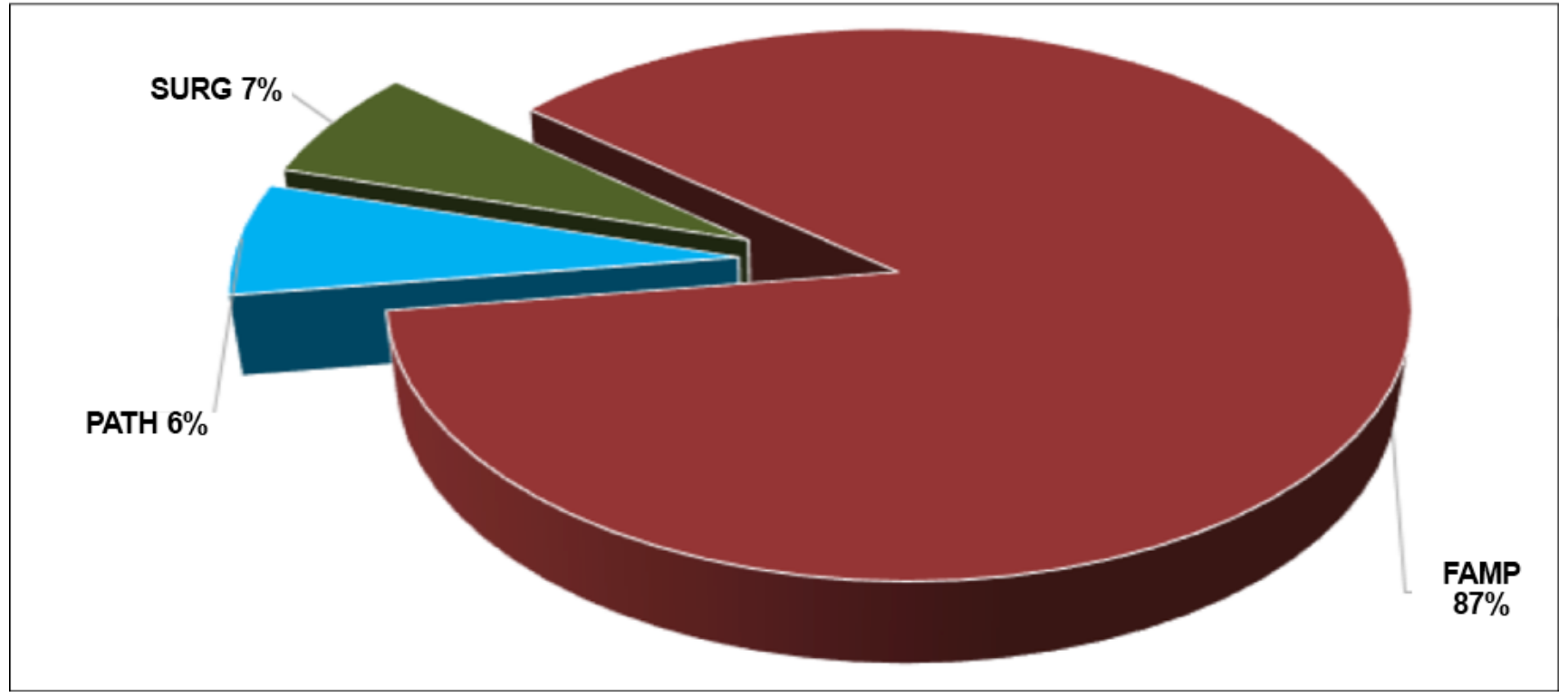

Acknowledgements 
The authors wish to thank Erin Parham, Senior Secretary, Department of Family Medicine, for assistance in data collection and preparation of this manuscript.

Presentations: Society of Teachers of Family Medicine Annual Spring Conference, May 2017, San Diego, California.

\section{Corresponding Author}

Valerie L. Hearns, MD

Department of Family Medicine, 1400 West 22nd Street, Sioux Falls, SD 57105. 605-357-1500. Fax: 605-357-1510

Valerie.Hearns@usd.edu

\section{Author Affiliations}

Valerie L. Hearns, MD - University of South Dakota Sanford School of Medicine, Department of Family Medicine

Susan M. Anderson, MD - University of South Dakota Sanford School of Medicine, Department of Family Medicine Wafa Akkad, MD - University of South Dakota Sanford School of Medicine, Department of Family Medicine

Benjamin Meyerink, MD - University of South Dakota Sanford School of Medicine

William E. Schweinle, PhD - University of South Dakota School of Health Sciences

\section{References}

1. Kozakowski SM, Travis A, Bentley A, Fetter G Jr. Entry of US medical school graduates into family medicine residencies: 2015-2016. Fam Med. 2016;48(9):688-695.

2. Kozakowski SM, Fetter G Jr, Bentley A. Results of the 2015 National Resident Matching Program: family medicine-a comparison with 1997 and 2009. Fam Med. 2015;47(9):717-721.

3. McKee ND, McKague MA, Ramsden VR, Poole RE. Cultivating interest in family medicine: family medicine interest group reaches undergraduate medical students. Can Fam Physician. 2007;53(4):661-665.

4. Senf JH, Campos-Outcalt D, Kutob R. Factors related to the choice of family medicine: a reassessment and literature review. J Am Board Fam Pract. 2003;16(6):502-512. https://doi.org/10.3122/jabfm.16.6.502.

5. Gill H, McLeod S, Duerksen K, Szafran O. Factors influencing medical students' choice of family medicine: effects of rural versus urban background. Can Fam Physician. 2012;58(11):e649-e657.

6. Schneider BN, Chessman A, Toffler W, Handler L, Steiner B, Biagioli FE. Medical Student Teaching and Recruiting: 50 Years of Balancing Two Educational Aims. Fam Med. 2017;49(4):282-288.

Copyright $@ 2017$ by the Society of Teachers of Family Medicine 